\title{
Practical Management of Respiratory Comorbidities in Patients with Rheumatoid Arthritis
}

\author{
James Bluett · Meghna Jani · Deborah P. M. Symmons
}

Received: June 5, 2017 / Published online: August 14, 2017

(C) The Author(s) 2017. This article is an open access publication

\begin{abstract}
Lung disease is one of the most common causes of extra-articular morbidity and mortality in patients with rheumatoid arthritis (RA). Development of pulmonary manifestations may be due to the systemic disease itself; to serious respiratory adverse events such as pneumonitis and infections secondary to therapy; or to lifestyle habits such as smoking. Rheumatologists often need to make important treatment decisions and plan future care in RA patients with respiratory comorbidities, despite the absence of clear evidence or consensus. In this review we evaluate the clinical assessment and management of RA-associated interstitial lung disease, bronchiectasis, serious (including opportunistic) infection, and smoking-related diseases. We summarize the international recommendations for the management of such conditions where
\end{abstract}

James Bluett and Meghna Jani are the joint first authors.

Enhanced content To view enhanced content for this article go to http://www.medengine.com/Redeem/ 28F8F0607A8E0037.

J. Bluett · M. Jani · D. P. M. Symmons ( $₫)$ Arthritis Research UK Centre for Epidemiology, Centre for Musculoskeletal Research, Division of Dermatological and Musculoskeletal Sciences, School of Biological Sciences, Faculty of Biology, Medicine and Health, University of Manchester, Manchester, UK

e-mail: Deborah.symmons@manchester.ac.uk available, refer to published best practice on the basis of scientific literature, and propose practical management suggestions to aid informed decision-making.

Keywords: Disease-modifying antirheumatic drugs; Respiratory tract diseases; Rheumatoid arthritis; Safety; Smoking

\section{INTRODUCTION}

Rheumatoid arthritis (RA) is a systemic inflammatory disorder. Although the predominant clinical feature of RA is inflammation of the synovial lining of joints, RA has numerous extra-articular manifestations. Lung disease is a major contributor to the extra-articular morbidity and mortality of RA [1]. Pulmonary manifestations of RA include RA-related interstitial lung disease (RA-ILD), bronchiectasis (BR), respiratory tract infections (RTI), pleural disease and, rarely, vascular disease [2]. In addition, because there is an increased prevalence of smoking in patients with RA [3], RA is associated with an increased incidence of lung cancer compared to the general population [4].

Over the last 15-20 years the management of RA has been transformed with an ongoing expansion in the armamentarium of treatments available. Treat-to-target guidelines advocate early treatment, with the aim of achieving and 
sustaining low disease activity (LDA) or remission $[5,6]$. Therefore, most patients with RA are likely to be treated with conventional synthetic and/or biologic disease-modifying antirheumatic drugs (csDMARDs; bDMARDs) early and throughout the course of their disease. Clinicians now commonly encounter RA patients with both uncontrolled articular disease and respiratory comorbidity in whom informed decisions about the benefits and risks of different potential treatments have to be made. In this narrative review, we focus on and summarize the evidence for best practice in the realworld management of the major respiratory comorbidities of RA: RA-ILD, BR, infection risk, and smoking-related airways disease; and management of the joint manifestations of RA in the context of respiratory comorbidity.

This article is based on previously conducted studies and does not involve any new studies of human or animal subjects performed by any of the authors.

\section{PREVALENCE OF SMOKING IN RA POPULATIONS AND RISKS OF SMOKING IN THE GENERAL POPULATION}

Cigarette smoking is a risk factor for the development of RA. In a meta-analysis of 16 observational studies, the summary odds ratio (OR) for developing RA for 20 or more pack-years of smoking (vs. never smoking) was 2.31 (1.55-3.41) in men and $1.75(1.52-2.02)$ in women [3]. The association is strongest for rheumatoid factor (RF)-positive RA. In the same meta-analysis, the summary ORs for RF-positive RA for men for ever, current, and past smokers (vs. never smokers) were 3.02 (2.35-3.88), 3.91 (2.78-5.50), and 2.46 (1.74-3.47), respectively [3]. This risk is thought to be related to gene-environment interaction. It is hypothesized that smoking leads to citrullination of proteins within the lung. In patients with one or more copies of the shared epitope (SE) this may be followed by the development of autoantibodies directed against citrullinated proteins (ACPA). Following exposure to a second trigger, subjects with the SE who are ACPA positive may then develop RA [7].

Since the majority of smokers with recent onset RA do not stop smoking [8], there is a higher prevalence of smoking in RA populations than in the general population. In a meta-analysis of four case-control studies involving 1415 RA patients and 1749 controls, Boyer et al. reported that the prevalence of smoking was approximately 50\% higher in patients with established RA than in their matched controls from the general population (summary OR 1.56; 95\% CI 1.35, 1.80) [9]. Between 21\% and 33\% of individuals with RA are current smokers and $50-75 \%$ are past smokers [8, 10-12].

In the general population, cigarette smoking is known to increase the risk of death from lung cancer, and chronic obstructive pulmonary disease (COPD) [13]. The risk rises with the duration of smoking and the number of cigarettes smoked per day. Strong inverse relationships are observed between the years since quitting smoking and deaths from lung cancer and COPD [13]. A systematic review of the literature up to 2007 concluded that, even in severe COPD, smoking cessation slows the rate of lung function decline and improves survival compared with continued smoking [14].

Smoking is also a strong risk factor for both sporadic idiopathic pulmonary fibrosis (IPF) and familial pulmonary fibrosis in the general population [15].

\section{INTERSTITIAL LUNG DISEASE AND BRONCHIECTASIS}

\section{Epidemiology}

RA-ILD is one of the most common respiratory comorbidities in RA and is associated with more severe RA [16]. Prevalence estimates vary between $10 \%$ and $30 \%[17,18]$ depending on the population studied and the imaging modality used for detection. Patients with RA-ILD have a more than threefold increased risk of premature death $[19,20]$ compared to RA patients without ILD, and have a median survival of 3 years following diagnosis [19]. Whilst 
RA is typically more common in women, RA-ILD is more frequent in men, with a ratio of 2:1 [21].

The association of RA with bronchiectasis (BR) has been recognized for many years. The prevalence of BR in RA has been estimated between $2 \%$ and $12 \%$ [22]. However, prevalence of up to $30 \%$ has been reported in studies using high-resolution computer tomography (HRCT) of the chest [22]. The coexistence of RA and BR is associated with higher mortality than BR alone [23].

\section{Predictors/Risk Factors}

Older age and male gender have been shown to be risk factors for RA-ILD in a number of studies $[24,25]$. Important clinical risk factors include markers of RA severity such as high levels of RF [24, 26], ACPA positivity [27, 28], subcutaneous nodules, and the human leukocyte antigen HLA-DR4 $[6,13,18]$. As noted above, there is a growing body of evidence that RA may commence within lung tissue triggered by citrullination of proteins within the lung, a hypothesis supported by the existence of ACPA-positive individuals with pulmonary involvement but no articular disease [29, 30].

RA usually precedes BR by 11-25 years $[31,32]$. Markers of RA disease severity [10] and disability do not seem to be associated with RA-BR [31, 32], but evidence is limited because of the absence of well-characterized cohorts and small numbers of patients. No marked differences have been found in immunoglobulin levels, autoantibody status, or complement levels in patients with RA-BR, compared with those with RA or BR alone [33]. Genetic susceptibility studies have again been limited by low numbers. One study found that the frequencies of HLA variants DQB1*0601, DQB1*0301, DQB1*0201, and DQA1*0501 were increased in subjects with $\mathrm{BR}$, with or without RA [34]. Another study showed that DRB1*0401, but not other RA-linked alleles, was significantly associated with RA-BR [35]. These results, however, require replication in larger cohorts.
It is not clear whether there is a direct association between smoking and RA-ILD or RA-BR. Some studies that concluded a link between smoking and RA-ILD actually presented the association between smoking and abnormal pulmonary function tests (PFTs), which can be difficult to interpret in this context [36]. Any association may additionally be mediated by seropositive status associated with ILD. More recent studies have failed to demonstrate a direct association between smoking and ILD $[24,37]$. An association between RA-BR and smoking has not been demonstrated, although evidence is limited [38-40]. However, smoking may be an important risk factor for infections and hence poorer outcomes in such patients, which is discussed later in this review.

\section{Clinical Features Specific to Patients with RA}

Whilst a proportion of RA patients may have subclinical ILD on HRCT and may be asymptomatic, the majority of patients with clinical ILD will present with exertional dyspnea, with or without a dry cough. Examination findings may include bibasal crepitations; however, finger clubbing is relatively unusual [41]. Symptoms of BR include wheeze, productive cough, copious amounts of sputum, hemoptysis, and pleuritic chest pain. There are no clinical features specific to RA-BR [42]. RA, ILD, and BR are all risk factors for RTI [43], suggesting that management of infection risk is particularly important in patients with overlap of these conditions.

\section{Long-Term Assessment and Management of RA-ILD/RA-BR}

\section{Assessment}

A thorough baseline assessment of pulmonary disease severity should include clinical features, PFTs, and imaging pattern/extent on HRCT-a high radiological fibrosis score on HRCT being a predictor of poor survival [44-46]. Such objective measures, repeated over time, allow a more accurate representation of disease trajectory and may help inform management decisions. Once 
the trajectory is established the frequency of monitoring can be adjusted accordingly [47].

Clinical assessment should include quantification of exercise tolerance using instruments such as the five-point Medical Research Council (MRC) breathlessness scale [48] and the 6-min-walk test [49]. Reduced walk distance and oxygen desaturation below $88 \%$ are poor prognostic factors in idiopathic ILD [50, 51]. PFTs should be performed in all patients with respiratory clinical features, confirmed RA-ILD, or prior to decisions about therapy. Low baseline forced vital capacity (FVC) and diffusing capacity of the lungs for carbon monoxide (DLCO) (FVC $<60 \%$ and DLCO $<40 \%$ of predicted values) are independent predictors of early death in patients with idiopathic ILD $[45,46]$. Importantly, a 6-12 months decline in FVC of at least $10 \%$, or a decline in DLCO of at least $15 \%$, is associated with increased mortality in idiopathic ILD [47, 52] (Box 1, Fig. 1).

Box 1 Recommendations for clinical assessment

Quantification of exercise tolerance using instruments
such as the five-point Medical Research Council
(MRC) breathlessness scale and the 6-min-walk test
Oxygen saturations of $<88 \%$ indicate poor
prognosis
Pulmonary function tests at regular intervals: frequency
directed by disease trajectory (Fig. 1 )
Forced vital capacity (FVC) $<60 \%$ and diffusing
capacity of the lungs for carbon monoxide (DLCO)
$<40 \%$ predicted indicate poor prognosis
$6-12$ months decline in FVC of $\geq 10 \%$, or a
decline in DLCO of $\geq 15 \%$, is associated with
increased mortality
RA-ILD: imaging using HRCT to evaluate extent of
fibrosis and subtype
$20 \%$ lung involvement and usual interstitial
pneumonia indicate poor prognosis

HRCT imaging is indicated in patients with clinical features of lung disease or in asymptomatic patients with a DLCO of less than $70 \%$ of predicted [53]. Individuals with HRCT findings consistent with usual interstitial pneumonia (UIP-basal dominant honeycomb cysts with little or no ground-glass change) have poorer prognosis than those with HRCT-detected features indicative of other types of idiopathic interstitial pneumonia (IIP) [54, 55]. There is no HRCT-based scoring in RA-ILD, although a small study suggested that the degree of interstitial changes detected was predictive of prognosis [56]. On the basis of these factors, a framework for assessment of RA-ILD has been proposed, focusing on risk assessment before initiation of biologic therapy and post-treatment monitoring [47] (Fig. 1). The approach is designed to help predict short-term progression irrespective of therapy. In the absence of clear evidence, such an approach, based on potential risk, may also be useful in RA-BR patients on DMARDs.

The possibility of underlying immune deficiency, particularly antibody deficiency, should be considered in with patients with RA-BR [57].

\section{Management}

There are no international guidelines on the management of RA-ILD or RA-BR because of limited evidence [58]. In the absence of such consensus, management of moderate to severe lung disease in patients with RA should be in collaboration with a respiratory physician. Given the association with markers of RA disease severity, the management of RA-ILD should include a focus on minimizing RA disease activity. Since the prognosis of RA-ILD is rather poor, a treatment which stabilizes the condition with no further deterioration may be viewed as successful.

Whilst several medications have been used in the management of RA-ILD and RA-BR, there are no randomized controlled trials (RCT) with conclusive evidence of benefit. Glucocorticoids have been used in the context of specific histological subtypes of RA-ILD such as non-specific interstitial pneumonia (NSIP), based on limited evidence from IPF. In steroid-responsive patients, azathioprine was traditionally thought to be of potential benefit [59]. However, the PANTHER trial [60], which evaluated response to the combination of 


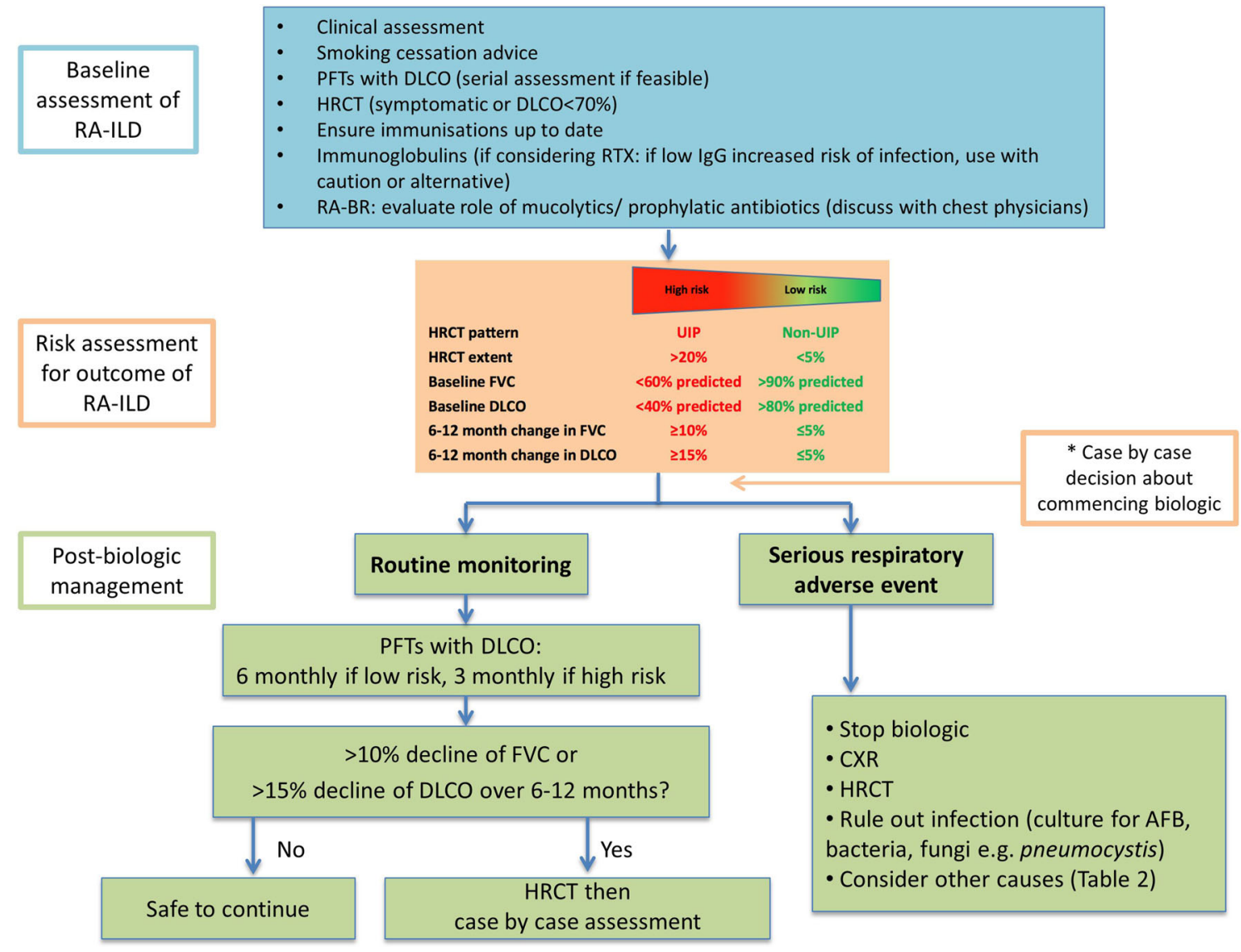

Fig. 1 Suggested algorithm for assessment, monitoring, and management of patients with RA-ILD. $A F B$ acid-fast bacilli, DLCO diffusion capacity of the lung for carbon monoxide, $F V C$ forced vital capacity, $H R C T$ high-resolution CT, NSIP nonspecific interstitial pneumonia, PFTs

prednisolone, azathioprine, and $\mathrm{N}$-acetylcysteine in patients with mild to moderate IPF, was prematurely stopped. Compared to placebo, a greater mortality (8 vs. 1 deaths), more hospitalizations ( 23 vs. 7 ), and more serious adverse events ( 24 vs. 8 ) were observed in the exposed group. Indeed use of glucocorticoids is associated with a significantly increased risk of infection in a dose-dependent fashion [61] (Table 1). Therefore, glucocorticoids should be used sparingly - at the lowest possible dose and the shortest duration-especially in patients with RA-ILD or RA-BR with a higher baseline infection risk.

Rituximab (RTX) appears promising in the treatment of connective tissue disease-related pulmonary function tests, RA-ILD rheumatoid arthritis-associated interstitial lung disease, UIP usual interstitial pneumonia. Reproduced, with permission by Nature. Initially published in [47]

ILD [62-64]. Data on the use of RTX in the treatment of RA lung disease are limited. The evidence, thus far, has not been encouraging in RA-ILD or RA-BR. In an open-label pilot study of ten patients with RA-ILD treated with RTX [65], one patient died of acute respiratory distress syndrome (ARDS)/possible pneumonia, 6 weeks post-treatment (no infective source identified). Of the seven patients who completed the 48-week follow-up, only one showed improvement in respiratory function, five were stable, and one deteriorated. Observational evidence in both RA-ILD and RA-BR has been inconclusive with no clear beneficial effect on disease progression or survival [66-69]. 
Table 1 Serious respiratory adverse events reported with drugs used in the treatment of rheumatoid arthritis

\begin{tabular}{|c|c|c|}
\hline Medication & Possible adverse event & Details \\
\hline Glucocorticoids & Infections $[61,80]$ & $\begin{array}{l}\text { Dose and duration of treatment related to } \\
\text { infection risk } \\
\text { Co-prescription of bDMARDs may further } \\
\text { increase risk }\end{array}$ \\
\hline \multicolumn{3}{|l|}{ csDMARDS } \\
\hline Methotrexate & $\begin{array}{l}\text { Pneumonitis }[81-83] \\
\text { Possible increase in infections }[84,85] \text { (poorer } \\
\text { response to pneumococcal vaccination) } \\
\text { Pulmonary lymphoproliferative disease } \\
{[73,74]}\end{array}$ & $\begin{array}{l}\text { Co-prescription of bDMARDs may increase risk } \\
\text { of chest/opportunistic infections }\end{array}$ \\
\hline Leflunomide & $\begin{array}{l}\text { Pneumonitis }[86,87] \\
\text { Progression of pulmonary nodules [88] with/ } \\
\text { without pneumothorax [89] }\end{array}$ & $\begin{array}{l}\text { Co-prescription of bDMARDs may increase risk } \\
\text { of chest/opportunistic infections }\end{array}$ \\
\hline Sulfasalazine & $\begin{array}{l}\text { Pneumonitis }[90,91] \\
\text { Eosinophilic pneumonias most commonly } \\
\text { reported }[92,93] \\
\text { Also reported with DRESS }[94,95]\end{array}$ & \\
\hline Hydroxychloroquine & $\begin{array}{l}\text { Rare cases of pneumonitis and DRESS } \\
\text { reported [96-98] }\end{array}$ & \\
\hline \multicolumn{3}{|l|}{ bDMARDS } \\
\hline TNFis & $\begin{array}{l}\text { Infection such as Streptococcus pneumoniae, } \\
\text { Haemophilus influenzae and opportunistic } \\
\text { infections (Mycobacterium tuberculosis, } \\
\text { non-tuberculous mycobacteria, Mycoplasma, } \\
\text { Legionella, Pneumocystis jirovecii) [99] } \\
\text { Pneumonitis [79] } \\
\text { Congestive heart failure [100] } \\
\text { Noninfectious granulomatous disease, e.g., } \\
\text { sarcoidosis [101, 102] } \\
\text { Pulmonary vasculitis [75, 103] }\end{array}$ & $\begin{array}{l}\text { Co-prescription of glucocorticoids (in patients } \\
\text { with high disease activity) further increases } \\
\text { infection risk }\end{array}$ \\
\hline Rituximab & $\begin{array}{l}\text { Rapidly progressive pneumonitis [104-106] } \\
\text { Infection (including opportunistic) [107] }\end{array}$ & Low IgG levels may help predict infection risk \\
\hline Abatacept & $\begin{array}{l}\text { Rare reports of pneumonitis [108] } \\
\text { Infection (including opportunistic) [107] }\end{array}$ & $\begin{array}{l}\text { In patients with a history of serious infections, } \\
\text { abatacept may have a better safety profile } \\
\text { compared with other biologics }\end{array}$ \\
\hline
\end{tabular}


Table 1 continued

\begin{tabular}{|c|c|}
\hline Medication & Possible adverse event \\
\hline Tocilizumab & Pneumonitis [109] \\
\hline & Infection (including opportunistic) [107] \\
\hline tsDMARDs & \\
\hline Tofacitinib & Infection (including opportunistic) [110] \\
\hline & $\begin{array}{l}\text { Rare cases of incident ILD and sarcoidosis } \\
{[111,112]}\end{array}$ \\
\hline
\end{tabular}

bDMARDs biologic disease-modifying antirheumatic drugs, DRESS drug reaction with eosinophilia and systemic symptoms, $I L D$ interstitial lung disease, nbDMARDs non-biologic disease-modifying antirheumatic drugs, tsDMARDs targeted synthetic disease-modifying antirheumatic drugs

Pirfenidone, an anti-fibrotic treatment, has demonstrated efficacy in IPF [70, 71] and has been approved by the National Institute of Health and Care Excellence in the UK and the FDA in the USA for use in patients with mild or moderate IPF. A phase II study of pirfenidone in RA-ILD is about to start [72].

The emphasis in RA-BR patients should be to minimize risk of infection. RA-BR patients with sputum production may benefit from mucolytics. According to British Thoracic Society guidelines, use of prophylactic antibiotics should be guided by sputum culture and can be considered in BR patients who have frequent exacerbations ( $\geq 3$ per annum) or serious infections requiring antibiotics or hospitalization [57]. Additionally those with reversible airways disease may benefit from a trial of inhaled corticosteroids [22]. Such decisions should be made under the joint care of a respiratory physician and rheumatologist. In RA-BR patients producing more than $20 \mathrm{ml}$ of purulent sputum over a 24 -h period, chest physiotherapy (including self-taught airway clearance techniques) and postural drainage may be considered [57].

It is important that all RA patients with pulmonary disease (and indeed all RA patients) should be regularly immunized against influenza and pneumococcus (see "Respiratory Infection").

In summary, we suggest that RA-ILD or RA-BR patients who require changes in treatment for their joint disease or ongoing monitoring of their respiratory status should be under the joint care of a respiratory physician and rheumatologist. Treatment decisions should involve a multidisciplinary approach as well as a careful discussion with the patient regarding the benefits and risks of treatment options available.

\section{Serious Respiratory Adverse Events Following Treatment}

The occurrence of serious respiratory adverse events (SRAEs) following commencement of RA treatment may be due to exacerbation of underlying lung disease, drug-induced ILD, or to other pulmonary complications (Table 1). Thorough investigation of the underlying etiology of SRAEs is essential as it can direct further management. A comprehensive evaluation for infection is imperative, especially in patients on high glucocorticoid doses, csDMARDs, bDMARDs, or targeted synthetic DMARDs (covered in the next section). Rare reported associations of therapies are important to consider in patients with atypical presentations (summarized in Table 1). For example lymphoproliferative disease (including non-Hodgkin's lymphoma) has been described with methotrexate (MTX) treatment and may regress following withdrawal [73, 74]. Paradoxical adverse events such as sarcoidosis and vasculitis have been reported with tumor necrosis factor inhibitors (TNFis) [75, 76]. 
"Pneumonitis" has been described with almost every drug used in the treatment of RA, emphasizing the importance of trying to disentangle whether the clinical features are due to infection, an exacerbation, or development of co-existent RA-ILD, or pulmonary disease triggered by the drug. In MTX-treated patients, diagnostic uncertainty and the lack of a gold standard test for MTX-pneumonitis leaves ambiguity about the true pattern of disease. For both MTX and leflunomide (LEF), the risk of incident lung disease in treated RCT patients appears reassuringly low from recent systematic reviews in RA patients [77]. Whilst a full critical review of drug-induced ILD is outside the scope of this paper, we signpost the reader to other reviews on this topic $[47,78,79]$.

\section{RESPIRATORY TRACT INFECTIONS}

\section{Respiratory Infection}

Respiratory tract infection or community-acquired pneumonia (CAP) is the most common type of infection seen in patients with RA [113], accounting for almost 50\% of RA hospital admissions for infection [114, 115].

\section{Predictors/Risk Factors}

The increased risk of CAP seen in RA is thought to be multifactorial because of patient-related, disease-related, and treatment-related factors (Table 2).

Cigarette smoking may contribute to the excess risk of CAP seen in patients with RA [8] both by increasing the disease severity of RA and by a direct effect on the lungs.

The risk of developing pneumonia in RA rises with increasing disease severity [116]. This may be due in part to physical immobility and in part to immune dysregulation [118, 119]. RA patients demonstrate a reduced response to influenza vaccination compared to healthy controls. This is not affected by the use of prednisolone or DMARDs [120].

\section{Clinical Features Specific to Patients with RA}

There are no specific clinical features of CAP in patients with RA. However, the mortality rate for CAP is significantly higher compared to patients without RA $[115,121]$ (22.2\% vs. $5.7 \%)$.

\section{Conventional Synthetic Disease-Modifying Antirheumatic Drugs and RTI}

The potential that medication may increase the risk of infection is of great importance to patients. It is known that fear of side effects, such as infection, reduces adherence which is associated with reduced response $[122,123]$.

The use of csDMARDs may predispose to infection via the adverse event of pancytopenia, particularly in patients with renal impairment [124]. Both LEF and MTX have been shown to impair neutrophil chemotaxis [85] and both are associated with an increased risk of infection. Of all antirheumatic medications, glucocorticoids are associated with the greatest increased risk of infection. There is an established dose-dependent risk of RTI associated with glucocorticoid therapy [80].

The majority of studies investigating the link between csDMARDs and RTI were observational studies and their results must be interpreted with caution. Although observational studies have the advantage of reflecting clinical practice they may also demonstrate channelling bias due to non-random assignment to therapy as a result of physician concerns about infection.

\section{Biologic Agents and Respiratory Tract Infection}

bDMARD use and the risk of RTI has been the subject of great debate in the literature. A meta-analysis using pooled data from RCTs which investigated the risk of serious infections in patients treated with TNFis [adalimumab (ADA), etanercept (ETN), and infliximab (INF)] found no significant increase in serious infection risk related to TNFi use (OR 1.21, 95\% CI 0.89-1.63) [125]. However, the strict inclusion criteria of RCTs 
Table 2 Risk factors for respiratory infection in patients with RA

\begin{tabular}{|c|c|}
\hline Risk factor & Level of risk \\
\hline Male gender & $\begin{array}{l}\text { 36\% RA admitted patients with CAP were male vs. } 26 \% \text { RA non-admitted patients, } \\
\quad P=0.022[115]\end{array}$ \\
\hline Older age & Mean age in RA with CAP vs. general population with CAP (years) 71 vs. 61 [115] \\
\hline Lower education level (per year) & HR 0.9 (95\% CI 0.9-1.0) [116] \\
\hline Ever smoking (vs. never smoking) & HR 1.3 (95\% CI 1.1-1.5) [116] \\
\hline Diabetes mellitus & HR $2.0(95 \%$ CI $1.6-2.5)[116]$ \\
\hline $\begin{array}{l}\text { Past medical history of pulmonary } \\
\text { disease }\end{array}$ & HR 3.8 (95\% CI 3.2-4.4) [116] \\
\hline Myocardial infarction & HR 2.1 (95\% CI 1.7-2.6) [116] \\
\hline Comorbidity score & HR 1.3 (95\% CI 1.2-1.3) [116] \\
\hline RA duration (per year) & HR 1.1 (95\% CI 1.0-1.2) [116] \\
\hline Number of previous DMARDs & HR 1.1 (95\% CI 1.1-1.2) [116] \\
\hline HAQ (per unit increase) & HR $2.0(95 \%$ CI $1.8-2.2)[116]$ \\
\hline \multirow[t]{2}{*}{ MTX } & No evidence of association $[115,116]$ \\
\hline & RR 1.16 (95\% CI 1.02-1.33) [117] \\
\hline LEF & HR $1.3(95 \%$ CI $1.0-1.5)[116]$ \\
\hline Sulfasalazine & No evidence of association $[116,117]$ \\
\hline Hydroxychloroquine & No evidence of association $[116,117]$ \\
\hline \multirow[t]{2}{*}{ Glucocorticoids } & HR 1.7 (95\% CI 1.5-21) [116] \\
\hline & HR 2.07 (95\% CI 2.37-3.08) [117] \\
\hline TNFi & No evidence of association $[116,117]$ \\
\hline
\end{tabular}

$R A$ rheumatoid arthritis, $C A P$ community-acquired pneumonia, $H R$ hazard ratio, $H A Q$ health assessment questionnaire, $M T X$ methotrexate, $L E F$ leflunomide, $T N F i$ tumor necrosis factor inhibitor

mean that the patients enrolled in trials are often substantially healthier than those who eventually receive the treatment once licensed. National registries were established to monitor the outcomes of biologic treatment in "real-life" patients. The British Society for Rheumatology Biologics Register (BSRBR-RA) found an increased risk of serious infections in RA patients treated with TNFi (vs. those treated with csDMARDs) (OR 1.2, 95\% CI 1.1-1.5) but there was no subgroup analysis for pneumonia [126]. The risk of infection appeared to be highest in the first 6 months of therapy. An increased risk of infection was also demonstrated in the Dutch DREAM registry in which the majority of infections (38.8\%) occurred in the respiratory tract [127]. The Italian GISEA registry reported that the risk of infection was higher in patients treated with INF or ADA compared to those treated with ETN $\left(\mathrm{HR}_{\mathrm{adj}}=2.24,95 \% \mathrm{CI}\right.$ 1.12-4.42 and 4.91, 95\% CI 2.71-8.91, respectively) [128].

Some patients prescribed RTX develop hypogammaglobulinemia, which may persist and which is associated with a trend towards higher rates of serious infections $[129,130]$. It is recommended that immunoglobulin levels are checked before commencing and 4-6 months after RTX infusions and before any retreatment [131]. 
A meta-analysis of trial data and an observational epidemiological study found the incidence rates of hospitalized pneumonia to be similar in RA patients prescribed abatacept and RA patients prescribed csDMARDs [132]. There are limited data on the risk of RTI in RA patients treated with the newer biologics (certolizumab, golimumab, and tocilizumab).

\section{Evidence-Based Management of CAP (Box 2)}

\section{Prevention}

Consideration of the risk of serious infection, including $\mathrm{CAP}$, should be undertaken prior to the requiring hospitalization in patients prescribed DMARDs [134]. The German RABBIT registry used data from 5044 RA patients and a replication cohort of 2990 to develop and evaluate a risk assessment tool which can be used to estimate the probability of a serious infection within 12 months of commencing DMARDs [135]. This tool demonstrates the high risk of infection conferred by the use of high dose glucocorticoids. For those patients with high disease activity but with a high risk of serious infections, clinicians may wish to consider commencing patients on combination csDMARDs rather than TNFi, or consider the use of bDMARDs associated with a lower incidence of infection, such as ETN or abatacept

Box 2 Prevention and treatment of CAP and its complications in patients with RA

\begin{tabular}{|c|c|}
\hline $\begin{array}{c}\text { RA patient at } \\
\text { diagnosis }\end{array}$ & $\begin{array}{l}\text { - Consider infection risk of immunosuppressives } \\
\text { - Offer pneumococcal polysaccharide vaccine } 23 \text { as a single dose } \\
\text { - Offer annual influenza vaccination } \\
\text { - Aim for lowest glucocorticoid dose to achieve disease remission }\end{array}$ \\
\hline $\begin{array}{l}\text { Development of } \\
\text { CAP }\end{array}$ & $\begin{array}{l}\text { - Treat CAP as per local guidelines } \\
\text { - Suspend csDMARDs if antibiotics commenced } \\
\text { - Suspend bDMARDs if an active, severe infection } \\
\text { - Recommence immunosuppressives once antibiotics completed and } \\
\text { clinical symptoms resolved }\end{array}$ \\
\hline $\begin{array}{c}\text { Development of } \\
\text { hematological } \\
\text { toxicity }\end{array}$ & $\begin{array}{l}\text { - Suspend immunosuppressives } \\
\text { - MTX: give folinic acid rescue therapy } \\
\text { - LEF: initiate washout }\end{array}$ \\
\hline Development of AKI & $\begin{array}{l}\text { - Suspend immunosuppressives } \\
\text { - MTX: give folinic acid rescue therapy }\end{array}$ \\
\hline
\end{tabular}

RA: rheumatoid arthritis; CAP: community acquired pneumonia; csDMARD: conventional synthetic disease modifying anti-rheumatic drug; bDMARD: biologic disease modifying antirheumatic drug; MTX: methotrexate; LEF: leflunomide.

commencement of immunosuppressives. Immunosuppressives should not be prescribed in patients with current serious infections [133]. A previous history of hospitalized infection is associated with an increased risk of bacterial infection
[128, 136]. Current American College of Rheumatology (ACR) guidelines suggest the use of combination csDMARDs rather than $\mathrm{TNFi}$, or abatacept rather than TNFi, but the level of 
evidence is very low [58]. The dose of glucocorticoids should be kept as low as possible in all patients.

In the general population, immunization against influenza reduces the incidence of hospital admissions and mortality amongst older priority $[149,150]$. Response to influenza immunization appears to be reduced in patients prescribed TNFi therapy but not MTX $[151,152]$.

The recommendations summarized in Box 3 are based on these guidelines and the current evidence available.

Box 3 Recommendations for pneumococcal and influenza immunization in patients with RA

- Pneumococcal vaccination should be offered to all patients with RA, regardless of treatment

- Pneumococcal vaccination should preferably take place prior to the commencement of DMARDs

- Pneumococcal revaccination after five years should be offered to patients with chronic renal disease

- Annual influenza vaccination should be offered to all patients with RA, regardless of treatment

( $>64$ years) patients and in younger adults has an overall effectiveness in preventing disease of $59 \%$ (95\% CI 51-67) [137, 138]. In patients with rheumatological and other "high-risk" comorbidities, influenza vaccination prevented 39 of 1000 healthy persons from being hospitalized for pneumonia/influenza or dying [139]. Pneumococcal vaccination in older adults reduces the incidence of pneumococcal pneumonia by 64\% per 1000 person years (pyr) amongst nursing home residents [140]. Current guidelines regarding influenza and pneumococcal vaccination in patients with RA are summarized in Table 3.

There is evidence of a decline in protection against pneumococcal vaccination over time with an associated increased risk of serious pneumococcal infection [144]. MTX, RTX, and abatacept, but not TNFi, reduce antibody response to the pneumococcal vaccination. We therefore recommend that patients should be vaccinated prior to receiving immunosuppressives wherever possible [145-148]. To date, no studies have evaluated whether there is additional benefit from boosting individuals with RA with a revaccination, but there is evidence for doing so in patients with asplenia or chronic renal disease. We recommend that evaluating the clinical benefit of revaccination of patients with RA after 5 years in reducing pneumococcal infection is considered a research

\section{Treatment of Infection}

Suspension of DMARD therapy during an infection is controversial. One large study investigating csDMARDs has shown that, while there is an increased risk of hospitalization due to pneumonia, there is no evidence to suggest that this translates to an increased risk of mortality $[115,117]$. The effects of continuing or withholding MTX and other DMARDs on the outcomes of CAP have not been studied. We recommend that this should therefore be a priority for future research.

Given the results from real-life data, current guidelines, and ex vivo studies, we recommend continuing immunosuppressive csDMARDS (MTX, LEF, and azathioprine) in those with mild infections that do not require antibiotics. However, in serious infections or those that require antibiotic therapy, we recommend withholding csDMARDs until the antibiotic course has been completed and clinical symptoms resolved. As MTX clearance is via the renal tract, impaired renal function can lead to the accumulation of MTX, increasing the risk of pancytopenia [153]. Given the risk of pancytopenia, patients who develop acute kidney injury with pneumonia and sepsis should be offered folinic acid rescue therapy to prevent MTX toxicity [154]. Patients prescribed LEF who 
Table 3 Guidelines on influenza and pneumococcal vaccination in patients with RA

\begin{tabular}{|c|c|c|}
\hline Guideline authors & Influenza & Pneumococcal \\
\hline BSR [141] & No guidance & $\begin{array}{l}\text { Immunization against pneumococcal... might } \\
\text { be indicated }\end{array}$ \\
\hline $\begin{array}{l}\text { The Joint Committee on } \\
\text { Vaccination and } \\
\text { Immunisation (JCVI) } \\
\text { [142] }\end{array}$ & $\begin{array}{l}\text { Where immunosuppression occurs because of } \\
\text { disease or treatment "It is difficult to define } \\
\text { at what level of immunosuppression a } \\
\text { patient could be considered to be at a } \\
\text { greater risk of the serious consequences of } \\
\text { influenza and should be offered influenza } \\
\text { vaccination. This decision is best made on } \\
\text { an individual basis and left to the patient's } \\
\text { clinician" }\end{array}$ & $\begin{array}{l}\text { Patients immunosuppressed because of disease } \\
\text { or treatment should receive a single dose of } \\
\text { pneumococcal immunization with } \\
\text { pneumococcal polysaccharide vaccine } \\
\text { (PPV) } 23\end{array}$ \\
\hline EULAR $[143]^{\mathrm{a}}$ & Strongly considered & $\begin{array}{l}\text { Strongly considered but it is not known if and } \\
\text { when pneumococcal revaccination should } \\
\text { take place }\end{array}$ \\
\hline $\operatorname{ACR}[58]^{\mathrm{b}}$ & $\begin{array}{l}\text { Recommended in patients starting/receiving } \\
\text { DMARDs or biologic agents }\end{array}$ & $\begin{array}{l}\text { Recommended in patients starting/receiving } \\
\text { DMARDs or biologic agents and a } \\
\text { one-time pneumococcal revaccination after } \\
5 \text { years }\end{array}$ \\
\hline
\end{tabular}

develop CAP and hematological toxicity such as neutropenia must stop LEF and a washout protocol should be initiated [154].

Neutropenia $\left(<1.5 \times 10^{9} / \mathrm{L}\right)$ is a recognized side effect of MTX. However, the clinical benefit of granulocyte colony stimulating factor (G-CSF) to RA patients with febrile neutropenia is yet to be fully investigated and evidence is limited to case series $[155,156]$. Some authors advocate the use of G-CSF for patients with drug-induced agranulocytosis (neutrophils $<0.5 \times 10^{9} / \mathrm{L}$ ), particularly in patients with poor prognostic features (neutrophil count $<0.1 \times 10^{9} / \mathrm{L}$, age over 65 years, severe infection, or multiple comorbidities) [155]. European guidelines for patients with chemotherapy-induced febrile neutropenia state that "G-CSF should not be used routinely as adjunct therapy for the treatment of uncomplicated fever and neutropenia, but may be considered in patients who are at a higher risk of infection-related complications and have prognostic factors that are predictive of poor clinical outcome" [157]. We would therefore recommend that G-CSF is not routinely offered to patients with pneumonia and drug-induced neutropenia. For patients with poor prognostic factors, such as septic shock, an individual case-by-case discussion involving hematology input should take place.

Guidelines recommend that glucocorticoid doses should be kept to a minimum in patients with RA because of the known association between glucocorticoid use and risk of pneumonia [80]. However, patients on glucocorticoids who develop severe infections may require a temporary increase in steroid dosage to avoid adrenal crisis [158].

Current guidance suggests that TNFi treatment should be suspended in patients with a serious infection (those requiring hospital 
admission or intravenous antibiotics) [133]. RTX is contraindicated in RA patients with active severe infection [159] as is tocilizumab [160].

\section{OPPORTUNISTIC INFECTIONS}

\section{Epidemiology}

Rates of mycobacterium tuberculosis (TB) in the general population vary widely internationally and are influenced by age and socioeconomic status. In Sweden, RA patients not treated with biologics had a two-fold increased risk of TB (95\% CI 1.2-3.4) compared with the general population [161]. It is unclear whether the increased risk in RA patients not treated with biologics is due to the disease or treatment of the disease with csDMARDs or glucocorticoids.

Opportunistic infections including Pneumocystis jiroveci, cryptococcal pneumonia, invasive pulmonary aspergillosis, nocardia, and viral pneumonia caused by cytomegalovirus (CMV) have also been described in patients with RA [99]. It is therefore important that clinicians are aware of the possibility of these diseases and their clinical presentations.

\section{Predictors/Risk Factors}

Treatment with TNFi is associated with an increased risk of developing TB. TNF plays a vital role in the host defense against TB [162]. Active symptomatic TB in RA patients exposed to TNFi is thought to be due predominantly to reactivation of latent TB [163].
A single case of TB was reported in the first TNFi RCT in 1999 [164]. "Real-world" observational studies soon confirmed that treatment with TNFi was associated with an increased risk of TB. In the BSRBR-RA, a multicenter observational cohort study of RA patients starting bDMARDs, the development of TB was greatest in those treated with INF and ADA and lowest with those treated with ETN [165]. It is now well recognized that ETN is associated with a lower risk of TB compared with INF and ADA $[165,166]$. In the Swedish registry, the crude incidence of TB was $118 / 100,000 \mathrm{pyr}$; the majority of cases $(62 \%)$ were extrapulmonary and 10 resulted in death. Screening and treatment of prior $\mathrm{TB}$ have been found, by the Spanish Biologics Registry, to result in a $78 \%$ reduction in the incidence of TB [167].

Information on the risk of reactivation of $\mathrm{TB}$ in patients treated with the newer biologics or tsDMARDs (RTX, abatacept, tocilizumab, certolizumab, golimumab, and tofacitinib) is limited to case reports and RCTs $[168,169]$. Interestingly, there is no reported increased risk of TB in patients with lymphoma treated with RTX [170].

\section{Clinical Features of TB Specific to Patients with RA}

TB that occurs in patients prescribed TNFi is more often extrapulmonary and disseminated at presentation compared with other cases of TB [163].

\section{Evidence-Based Management of latent TB (Box 4)}

On the basis of the evidence presented, we recommend screening and treatment of patients 
Box 4 Recommendations for screening and treatment of patients with latent TB commencing bDMARDs

- Prior to commencing biologic therapy, all patients should be screened for mycobacterial infection in accordance with the latest national guidelines

- Active mycobacterial infection needs to be adequately treated before biologic therapy can be started

- Prior to commencing biologic therapy, consideration of prophylactic anti-TB therapy (as directed by the latest National guidelines) should be given to patients with evidence of potential latent disease (e.g. positive tuberculin skin test, positive interferon-gamma release assay, past history of TB or abnormal chest X-ray).

- All patients commenced on biologic therapies should be closely monitored for mycobacterial infections. This should continue for at least 6 months after stopping treatment due to the prolonged elimination phase of the drug

- Patients who develop symptoms suggestive of mycobacterial infections should receive full anti-mycobacterial chemotherapy whilst awaiting confirmatory investigations, but may continue with anti-TNF therapy if clinically indicated.

with latent $\mathrm{TB}$ to prevent reactivation in patients starting TNFi. Treatment of latent TB should be in line with national guidelines. Given the ongoing concern of risk of active TB with immunosuppressive biologics, we recommend that these guidelines are followed for all patients starting bDMARDs. EULAR guidelines suggest the use of RTX in patients with latent TB who have contraindications to the use of chemoprophylaxis [171].

\section{LUNG CANCER AND OTHER SMOKING-RELATED RESPIRATORY DISEASES}

\section{Epidemiology of Lung Cancer in RA}

In a meta-analysis of 12 observational studies, Smitten et al. reported that, compared to the general population, the overall risk of lung cancer was increased in patients with RA: standardized incidence ratio (SIR) 1.63 (95\% CI $1.43,1.87)$ [172]. This represents a substantial burden given the high background risk of lung cancer in the general population. Smoking is the strongest risk factor for lung cancer in the general population. The meta-analysis by Smitten et al. did not explore the role of smoking in the incidence of lung cancer in patients with RA. Mercer et al. compared the risk of cancer in 3771 biologic-naïve individuals with RA enrolled by the BSRBR-RA from 2002 to 2009 with the risk in the general population for England [173]. During 13,315 pyrs of follow-up, 46 lung cancers were reported to the National Cancer Registry giving a standardized incidence ratio (SIR) of 2.39 (95\% CI 1.75, 3.19). Lung cancer was the most common cancer in this cohort. The risk was increased for men (SIR 2.01; 95\% $1.15,3.26$ ) and women (SIR 2.66; 95\% CI 1.79, 3.80). Smoking was found to be a risk factor for all cancers combined within this cohort (RR for current smokers (vs. never smokers) 2.66; 95\% CI 1.71, 4.15; for former smokers $2.14 ; 1.43$, 3.19).

Joseph et al. conducted a study in 5677 patients with incident RA identified from the UK Clinical Practice Research Datalink (CPRD) [8]. of whom $60 \%$ were ever smokers and $26 \%$ current smokers [8]. Current smokers with incident RA were 23 times more likely to die 
from lung cancer than RA patients who had never smoked [subdistribution hazard ratio (SHR) 23.2; 95\% CI 5.2-105)]. This is of similar magnitude to the risk of smoking in the general population in relation to lung cancer in recent times [13]. Former smokers with RA also had an increased risk of death due to lung cancer compared to never smokers (SHR 7.8; 95\% CI $1.7,35.0)$ [8].

There is no evidence that any DMARD therapies contribute to the high risk of lung cancer in RA.

\section{Smoking and COPD in RA}

In a study from the Mayo Clinic, the lifetime risk of developing obstructive lung disease (OLD) (which included COPD, asthma, bronchiectasis, obstructive bronchiolar disorders, and ILD-associated airflow obstruction) was significantly higher in individuals with RA compared to the general population $(9.6 \%$ vs. $6.2 \%$ ) (adjusted HR 1.54; 95\% CI 1.01, 2.34) [174]. Of the 52 patients who developed OLD, $46(88 \%)$ had COPD. Smoking was the strongest risk factor for the development of OLD in this cohort, followed by RF positivity and male gender. The risk of OLD was more than four times higher in ever than in never smokers (HR 4.38; 95\% CI 2.14, 8.99) and nearly three times higher in RF-positive RA independent of smoking status [174, 175]. Steroid use (ever) and DMARD use (ever) were associated with an increased risk of OLD, but MTX use was not. The development of OLD was associated with worse survival (adjusted HR 2.09; 95\% CI 1.47, 2.97).

In the study by Joseph et al. from the CPRD, the prevalence of COPD was $1 \%$ in never smokers, $7 \%$ in former smokers, and $6 \%$ in current smokers $\left(\chi^{2}(2)=36, p<0.001\right)$ during a mean follow-up of 4.5 years from diagnosis [8].

\section{Benefit of Smoking Cessation in RA}

Current smoking in RA has been independently linked with higher titers of RF, worse disability, and lower response rates to MTX and TNFi $[176,177]$. Joseph et al. found that all-cause mortality fell by $15 \%$ for each additional year of smoking cessation in heavy smokers and $10 \%$ in former light smokers with RA. The risk of death from respiratory causes fell by $21 \%$ per year in former heavy smokers. The risk of death due to RTI fell by $30 \%$ for each additional year of smoking cessation in former light smokers with RA [8]. However, there was no observable benefit from smoking cessation with respect to death from lung cancer either for former light or for heavy smokers, nor for RTI in former heavy smokers.

Promoting smoking cessation amongst patients with RA could potentially reduce the risk of CAP and lung cancer for these patients. However, in a large multinational study, almost one-third of rheumatologists and two-thirds of rheumatology nurses reported that they did not give smoking cessation advice to most of their patients [178]. Efforts to develop smoking cessation programmes specific for patients with RA have had mixed success. Harris et al. developed visual materials which emphasized the hazards of smoking in RA [179]. Following a media campaign using these materials, they found a $45 \%$ increased awareness amongst RA patients that smoking could interfere with the treatment of RA. The materials did not address the link between smoking and respiratory comorbidity in RA. Aimer et al. identified five factors which were barriers to smoking cessation in a New Zealand RA population: lack of support, limited knowledge of the relationship between smoking and RA, uncontrolled pain, inability to exercise, and using smoking as a coping strategy [180]. They then developed an intervention to address these issues but found, in a small pilot study, that the addition of RA-specific support and information was no more effective than the standard intervention of brief advice plus nicotine replacement therapy [181].

We recommend that RA patients should be asked about their smoking status at every consultation and that smoking cessation advice and further support such as nicotine replacement therapy should be made available [182]. 


\section{CONCLUSIONS}

We have reviewed the evidence concerning the burden and evidence-based management of the most common respiratory comorbidities in RA (interstitial lung disease, bronchiectasis, infection, and lung cancer). We have offered recommendations concerning the management of rheumatoid joint disease in the context of pre-existing lung disease or high risk of respiratory infection or reactivation of latent TB. Often good evidence is missing and we have highlighted areas where further research is needed.

\section{ACKNOWLEDGEMENTS}

No funding or sponsorship was received for this study or publication of this article. All named authors meet the International Committee of Medical Journal Editors (ICMJE) criteria for authorship for this manuscript, take responsibility for the integrity of the work as a whole, and have given final approval to the version to be published. We acknowledge the contribution of Profs. Will Dixon, Eric Matteson. and Dr Nik Hirani in the development of the original management recommendations for RA-ILD.

Disclosures. Meghna Jane and James Bluett are NIHR academic clinical lecturers in rheumatology. Deborah Symmons has nothing to disclose.

Compliance with Ethics Guidelines. This article is based on previously conducted studies and does not involve any new studies of human or animal subjects performed by any of the authors.

Open Access. This article is distributed under the terms of the Creative Commons Attribution-NonCommercial 4.0 International License (http://creativecommons.org/licenses/ by-nc/4.0/), which permits any noncommercial use, distribution, and reproduction in any medium, provided you give appropriate credit to the original author(s) and the source, provide a link to the Creative Commons license, and indicate if changes were made.

\section{REFERENCES}

1. Nannini C, Ryu JH, Matteson EL. Lung disease in rheumatoid arthritis. Curr Opin Rheumatol. 2008;20(3):340-6.

2. Shaw M, Collins BF, Ho LA, Raghu G. Rheumatoid arthritis-associated lung disease. Eur Respir Rev. $2015 ; 24: 1-16$.

3. Sugiyama D, Nishimura K, Tamaki K, et al. Impact of smoking as a risk factor for developing rheumatoid arthritis: a meta-analysis of observational studies. Ann Rheum Dis. 2010;69(01):70-81.

4. Khurana R, Wolf R, Berney S, Caldito G, Hayat S, Berney SM. Risk of development of lung cancer is increased in patients with rheumatoid arthritis: a large case control study in US veterans. J Rheumatol. 2008;35(9):1704-8.

5. Smolen JS, Breedveld FC, Burmester GR, et al. Treating rheumatoid arthritis to target: 2014 update of the recommendations of an international task force. Ann Rheum Dis. 2015;75:1-13.

6. Smolen JS, Landewe R, Bijlsma J, et al. EULAR recommendations for the management of rheumatoid arthritis with synthetic and biological disease-modifying antirheumatic drugs: 2016 update. Ann Rheum Dis. 2017;76:960-77.

7. Klareskog L, Catrina AI, Paget S. Rheumatoid arthritis. Lancet. 2010;373(9664):659-72.

8. Joseph RM, Movahedi M, Dixon WG, Symmons DP. Smoking-related mortality in patients with early rheumatoid arthritis: a retrospective cohort study using the clinical practice research datalink. Arthritis Care Res. 2016;68(11):1598-606.

9. Boyer JF, Gourraud PA, Cantagrel A, Davignon JL, Constantin A. Traditional cardiovascular risk factors in rheumatoid arthritis: a meta-analysis. Jt Bone Spine. 2011;78(2):179-83.

10. Nyhall-Wahlin BM, Petersson IF, Nilsson JA, Jacobsson LT, Turesson C. High disease activity disability burden and smoking predict severe extra-articular manifestations in early rheumatoid arthritis. Rheumatology (Oxford). 2009;48(4):416-20.

11. de Rooy DPC, van Nies JAB, Kapetanovic MC, et al. Smoking as a risk factor for the radiological severity 
of rheumatoid arthritis: a study on six cohorts. Ann Rheum Dis. 2014;73(7):1384-7.

12. Vesperini V, Lukas C, Fautrel B, Le Loet X, Rincheval N, Combe B. Association of tobacco exposure and reduction of radiographic progression in early rheumatoid arthritis: results from a French multicenter cohort. Arthritis Care Res. 2013;65(12):1899-906.

13. Thun MJ, Carter BD, Feskanich D, et al. 50-year trends in smoking-related mortality in the United States. N Engl J Med. 2013;368(4):351-64.

14. Godtfredsen NS, Lam TH, Hansel TT, et al. COPD-related morbidity and mortality after smoking cessation: status of the evidence. Eur Respir J. 2008;32(4):844-53.

15. Oh CK, Murray LA, Molfino NA. Smoking and idiopathic pulmonary fibrosis. Pulm Med. 2012;2012:808260.

16. Turesson C, O'Fallon WM, Crowson CS, Gabriel SE, Matteson EL. Extra-articular disease manifestations in rheumatoid arthritis: incidence trends and risk factors over 46 years. Ann Rheum Dis. 2003;62:722-7.

17. Olson AL, Swigris JJ, Sprunger DB, et al. Rheumatoid arthritis-interstitial lung disease-associated mortality. Am J Respir Crit Care Med. 2011;183:372-8.

18. Castelino FV, Varga J. Interstitial lung disease in connective tissue diseases: evolving concepts of pathogenesis and management. Arthritis Res Ther. 2010;12:213.

19. Bongartz T, Nannini C, Medina-Velasquez YF, et al. Incidence and mortality of interstitial lung disease in rheumatoid arthritis: a population-based study. Arthritis Rheum. 2010;62:1583-91.

20. American Thoracic Society, European Respiratory Society. American Thoracic Society/European Respiratory Society international multidisciplinary consensus classification of the idiopathic interstitial pneumonias. Am J Respir Crit Care Med. 2002;165:277-304.

21. de Lauretis A, Veeraraghavan S, Renzoni E. Review series: aspects of interstitial lung disease: connective tissue disease-associated interstitial lung disease: how does it differ from IPF? How should the clinical approach differ? Chronic Respir Dis. 2011;8:53-82.

22. Wilczynska MM, Condliffe AM, McKeon DJ. Coexistence of bronchiectasis and rheumatoid arthritis: revisited. Respir Care. 2013;58:694-701.

23. De Soyza A, McDonnell MJ, Goeminne PC, et al. Bronchiectasis rheumatoid overlap syndrome
(BROS) is an independent risk factor for mortality in patients with bronchiectasis: a multicentre cohort study. Chest. 2017;151(6):1247-54.

24. Mori S, Koga Y, Sugimoto M. Different risk factors between interstitial lung disease and airway disease in rheumatoid arthritis. Respir Med. 2012;106:1591-9.

25. Assayag D, Lubin M, Lee JS, King TE, Collard HR, Ryerson CJ. Predictors of mortality in rheumatoid arthritis-related interstitial lung disease. Respirology. 2014;19:493-500.

26. Schernthaner G, Scherak O, Kolarz G, Kummer F. Seropositive rheumatoid arthritis associated with decreased diffusion capacity of the lung. Ann Rheum Dis. 1976;35:258-62.

27. Giles JT, Danoff SK, Sokolove J, et al. Association of fine specificity and repertoire expansion of anticitrullinated peptide antibodies with rheumatoid arthritis associated interstitial lung disease. Ann Rheum Dis. 2014;73:1487-94.

28. Zhu J, Zhou Y, Chen X, Li J. A metaanalysis of the increased risk of rheumatoid arthritis-related pulmonary disease as a result of serum anticitrullinated protein antibody positivity. J Rheumatol. 2014;41:1282-9.

29. Fischer A, Solomon JJ, Du Bois RM, et al. Lung disease with anti-CCP antibodies but not rheumatoid arthritis or connective tissue disease. Respir Med. 2012;106:1040-7.

30. Gizinski AM, Mascolo M, Loucks JL, et al. Rheumatoid arthritis (RA)-specific autoantibodies in patients with interstitial lung disease and absence of clinically apparent articular RA. Clin Rheumatol. 2009;28:611-3.

31. Shadick NA, Fanta CH, Weinblatt ME, O'Donnell W, Coblyn JS. Bronchiectasis. A late feature of severe rheumatoid arthritis. Medicine. 1994;73:161-70.

32. Bamji A, Cooke N. Rheumatoid arthritis and chronic bronchial suppuration. Scand J Rheumatol. 1985;14:15-21.

33. McMahon MJ, Swinson DR, Shettar S, et al. Bronchiectasis and rheumatoid arthritis: a clinical study. Ann Rheum Dis. 1993;52:776-9.

34. Hillarby MC, McMahon MJ, Grennan DM, et al. HLA associations in subjects with rheumatoid arthritis and bronchiectasis but not with other pulmonary complications of rheumatoid disease. $\mathrm{Br}$ J Rheumatol. 1993;32:794-7.

35. Toussirot E, Despaux J, Wendling D. Increased frequency of HLA-DRB1*0401 in patients with RA and bronchiectasis. Ann Rheum Dis. 2000;59:1001. 
36. Saag KG, Kolluri S, Koehnke RK, et al. Rheumatoid arthritis lung disease. Determinants of radiographic and physiologic abnormalities. Arthritis Rheum. 1996;39(10):1711-9.

37. Biederer J, Schnabel A, Muhle C, Gross WL, Heller M, Reuter M. Correlation between HRCT findings, pulmonary function tests and bronchoalveolar lavage cytology in interstitial lung disease associated with rheumatoid arthritis. Eur Radiol. 2004;14:272-80.

38. McDonagh J, Greaves M, Wright AR, Heycock C, Owen JP, Kelly C. High resolution computed tomography of the lungs in patients with rheumatoid arthritis and interstitial lung disease. $\mathrm{Br} \mathrm{J}$ Rheumatol. 1994;33(2):118-22.

39. Kochbati S, Boussema F, Ben Miled $M$, et al. Bronchiectasis in rheumatoid arthritis. High resolution computed pulmonary tomography. La Tunisie medicale. 2003;81(10):768-73 (Article in French).

40. Despaux J, Manzoni P, Toussirot E, Auge B, Cedoz JP, Wendling D. Prospective study of the prevalence of bronchiectasis in rheumatoid arthritis using high-resolution computed tomography. Rev Rhum Engl Ed. 1998;65(7-9):453-61.

41. Dawson JK, Fewins HE, Desmond J, Lynch MP, Graham DR. Fibrosing alveolitis in patients with rheumatoid arthritis as assessed by high resolution computed tomography, chest radiography, and pulmonary function tests. Thorax. 2001;56(8):622-7.

42. Barker AF. Bronchiectasis. N Engl J Med. 2002;346:1383-93.

43. Dhasmana DJ, Wilson R. Bronchiectasis and autoimmune disease. Eur Respir Monogr. 2011;52:192-210.

44. Ryerson CJ, Urbania TH, Richeldi L, et al. Prevalence and prognosis of unclassifiable interstitial lung disease. Eur Respir J. 2013;42:750-7.

45. Egan JJ, Martinez FJ, Wells AU, Williams T. Lung function estimates in idiopathic pulmonary fibrosis: the potential for a simple classification. Thorax. 2005;60:270-3.

46. Ley B, Ryerson CJ, Vittinghoff E, et al. A multidimensional index and staging system for idiopathic pulmonary fibrosis. Ann Intern Med. 2012;156:684-91. doi:10.7326/0003-4819-156-10201205150-00.

47. Jani M, Hirani N, Matteson EL, Dixon WG. The safety of biologic therapies in RA-associated interstitial lung disease. Nat Rev Rheumatol. 2014;10:284-94.
48. Stenton C. The MRC breathlessness scale. Occup Med (Lond). 2008;58:226-7.

49. Raghu G, Collard HR, Egan JJ, et al. An official ATS/ ERS/JRS/ALAT statement: idiopathic pulmonary fibrosis: evidence-based guidelines for diagnosis and management. Am J Respir Crit Care Med. 2011;183(6):788-824.

50. Raghu G, Collard HR, Egan JJ, et al. An official ATS/ ERS/JRS/ALAT statement: idiopathic pulmonary fibrosis: evidence-based guidelines for diagnosis and management. Am J Respir Crit Care Med. 2011;183:788-824.

51. Raghu G, Rochwerg B, Zhang Y, et al. An official ATS/ERS/JRS/ALAT clinical practice guideline: treatment of idiopathic pulmonary fibrosis: an update of the 2011 clinical practice guideline. Am J Respir Crit Care Med. 2015;192:e3-19.

52. Latsi PI, du Bois RM, Nicholson AG, et al. Fibrotic idiopathic interstitial pneumonia: the prognostic value of longitudinal functional trends. Am J Respir Crit Care Med. 2003;168:531-7.

53. Hamblin MJ, Horton MR. Rheumatoid arthritis-associated interstitial lung disease: diagnostic dilemma. Pulm Med. 2011;2011:872120.

54. Flaherty KR, Thwaite EL, Kazerooni EA, et al. Radiological versus histological diagnosis in UIP and NSIP: survival implications. Thorax. 2003;58:143-8.

55. Kim EJ, Elicker BM, Maldonado F, et al. Usual interstitial pneumonia in rheumatoid arthritis-associated interstitial lung disease. Eur Respir J. 2010;35:1322-8.

56. Sathi N, Urwin T, Desmond S, Dawson JK. Patients with limited rheumatoid arthritis-related interstitial lung disease have a better prognosis than those with extensive disease. Rheumatology (Oxford). 2011;50:620.

57. Pasteur MC, Bilton D, Hill AT. Group BTSBn-CG. British Thoracic Society guideline for non-CF bronchiectasis. Thorax. 2010;65:i1-58.

58. Singh JA, Saag KG, Bridges SL Jr, et al. 2015 American College of Rheumatology guideline for the treatment of rheumatoid arthritis. Arthritis Care Res. 2016;68(1):1-25.

59. Raghu G, Depaso WJ, Cain K, et al. Azathioprine combined with prednisone in the treatment of idiopathic pulmonary fibrosis: a prospective double-blind, randomized, placebo-controlled clinical trial. Am Rev Respir Dis. 1991;144(2):291-6.

60. Idiopathic Pulmonary Fibrosis Clinical Research, Raghu G, Anstrom KJ, King TE Jr, Lasky JA, Martinez 
FJ. Prednisone, azathioprine, and $N$-acetylcysteine for pulmonary fibrosis. $\mathrm{N}$ Engl J Med. 2012;366(21):1968-77.

61. Dixon WG, Abrahamowicz M, Beauchamp ME, et al. Immediate and delayed impact of oral glucocorticoid therapy on risk of serious infection in older patients with rheumatoid arthritis: a nested case-control analysis. Ann Rheum Dis. 2012;71(7):1128-33.

62. Sumida H, Asano Y, Tamaki Z, et al. Successful experience of rituximab therapy for systemic sclerosis-associated interstitial lung disease with concomitant systemic lupus erythematosus. J Dermatol. 2014;41(5):418-20.

63. Keir GJ, Maher TM, Hansell DM, Denton CP, Ong $\mathrm{VH}$, Singh S, et al. Severe interstitial lung disease in connective tissue disease: rituximab as rescue therapy. Eur Respir J. 2012;40(3):641-8.

64. Bosello SL, De Luca G, Rucco M, et al. Long-term efficacy of B cell depletion therapy on lung and skin involvement in diffuse systemic sclerosis. Semin Arthritis Rheum. 2015;44(4):428-36.

65. Matteson E, Bongartz T, Ryu JH, Crowson C, Hartman T, Dellaripa PF. Open-label, pilot study of the safety and clinical effects of rituximab in patients with rheumatoid arthritis associated interstitial pneumonia. Open J Rheumatol Autoimmune Dis. 2012;2:53-8.

66. Dass S, Atzeni F, Vital EM, et al. Safety of rituximab in patients with rheumatoid arthritis and concomitant lung disease. Rheumatology. 2011;50:iii121.

67. Md Yusof MY, Kabia A, Dass S, Vital EM, Beirne P, Emery P. Efficacy and safety of rituximab in rheumatoid arthritis patients with concomitant interstitial lung disease: 10-year experience at single centre. Ann Rheum Dis. 2015;74:251.

68. Becerra E, Cambridge G, Leandro MJ. Safety and efficacy of rituximab in patients with rheumatoid arthritis and lung involvement. Arthritis Rheum. 2012;64:S220.

69. Druce K, Iqbal K, Watson K, Symmons DPM, Hyrich KL, Kelly C. Mortality in patients with rheumatoid arthritis and interstitial lung disease treated with first line TNFi or rituximab therapies. Arthritis Rheumatol. 2016;68:4092-4.

70. Noble PW, Albera C, Bradford WZ, Costabel U, Glassberg MK, Kardatzke D, et al. Pirfenidone in patients with idiopathic pulmonary fibrosis (CAPACITY): two randomised trials. Lancet. 2011;377(9779):1760-9.
71. Taniguchi H, Ebina M, Kondoh Y, et al. Pirfenidone in idiopathic pulmonary fibrosis. Eur Respir J. 2010;35(4):821-9.

72. Rosas I. Phase ll study of pirfenidone in patients with RAILD. In: ClinicalTrials.gov. Bethesda (MD): National Library of Medicine (US). 2000. https:// clinicaltrials.gov/ct2/show/study/NCT02808871. NLM Identifier: NCT02808871. Accessed 10 Apr 2017.

73. Hoshida Y, Xu J-X, Fujita S, et al. Lymphoproliferative disorders in rheumatoid arthritis: clinicopathological analysis of 76 cases in relation to methotrexate medication. J Rheumatol. 2007;34:322-31.

74. Rizzi R, Curci P, Delia M, et al. Spontaneous remission of "methotrexate-associated lymphoproliferative disorders" after discontinuation of immunosuppressive treatment for autoimmune disease. Review of the literature. Med Oncol. 2009;26:1-9.

75. Jani M, Dixon WG, Kearsley-Fleet L, et al. Drug-specific risk and characteristics of lupus and vasculitis-like events in patients with rheumatoid arthritis treated with TNFi: results from BSRBR-RA. RMD Open. 2017;3:e000314.

76. Perez-Alvarez R, Pérez-de-Lis $M$, Ramos-Casals $M$. Biologics-induced autoimmune diseases. Curr Opin Rheumatol. 2013;25:56-64.

77. Conway R, Low C, Coughlan RJ, O'Donnell MJ, Carey JJ. Methotrexate use and risk of lung disease in psoriasis, psoriatic arthritis, and inflammatory bowel disease: systematic literature review and meta-analysis of randomised controlled trials. BMJ. 2015;350:h1269.

78. Hadjinicolaou AV, Nisar MK, Bhagat S, Parfrey H, Chilvers ER, Östör AJK. Non-infectious pulmonary complications of newer biological agents for rheumatic diseases-a systematic literature review. Rheumatology. 2011;50(12):2297-305.

79. Roubille C, Haraoui B. Interstitial lung diseases induced or exacerbated by DMARDS and biologic agents in rheumatoid arthritis: a systematic literature review. Semin Arthritis Rheum. 2014;43(5):613-26.

80. Dixon WG, Suissa S, Hudson M. The association between systemic glucocorticoid therapy and the risk of infection in patients with rheumatoid arthritis: systematic review and meta-analyses. Arthritis Res Therapy. 2011;13(4):R139.

81. Chikura B, Sathi N, Lane S, Dawson JK. Variation of immunological response in methotrexate-induced 
pneumonitis. Rheumatology (Oxford). 2008;47(11):1647-50.

82. Collins K, Aspey H, Todd A, Saravanan V, Rynne M, Kelly C. Methotrexate pneumonitis precipitated by switching from oral to parenteral administration. Rheumatology (Oxford). 2008;47(1):109-10.

83. Kremer JM, Alarcon GS, Weinblatt ME, et al. Clinical, laboratory, radiographic, and histopathologic features of methotrexate-associated lung injury in patients with rheumatoid arthritis: a multicenter study with literature review. Arthritis Rheum. 1997;40(10):1829-37.

84. van der Veen MJ, van der Heide A, Kruize AA, Bijlsma JW. Infection rate and use of antibiotics in patients with rheumatoid arthritis treated with methotrexate. Ann Rheum Dis. 1994;53(4):224-8.

85. Kraan MC, de Koster BM, Elferink JG, Post WJ, Breedveld FC, Tak PP. Inhibition of neutrophil migration soon after initiation of treatment with leflunomide or methotrexate in patients with rheumatoid arthritis: findings in a prospective, randomized, double-blind clinical trial in fifteen patients. Arthritis Rheum. 2000;43(7):1488-95.

86. Ju JH, Kim S-I, Lee J-H, et al. Risk of interstitial lung disease associated with leflunomide treatment in Korean patients with rheumatoid arthritis. Arthritis Rheum. 2007;56:2094-6.

87. Sawada T, Inokuma S, Sato T, et al. Leflunomide-induced interstitial lung disease: prevalence and risk factors in Japanese patients with rheumatoid arthritis. Rheumatol (Oxford). 2009;48:1069-72.

88. Yoshikawa GT, Dias GA, Fujihara S, et al. Formation of multiple pulmonary nodules during treatment with leflunomide. J Bras Pneumol. 2015;41(3):281-4.

89. Kim SH, Yoo WH. Recurrent pneumothorax associated with pulmonary nodules after leflunomide therapy in rheumatoid arthritis: a case report and review of the literature. Rheumatol Int. 2011;31(7):919-22.

90. Yamakado S, Yoshida Y, Yamada T, Kishida T, Kobayashi M, Nomura T. Pulmonary infiltration and eosinophilia associated with sulfasalazine therapy for ulcerative colitis: a case report and review of literature. Intern Med. 1992;31:108-13.

91. Parry SD, Barbatzas C, Peel ET, Barton JR. Sulphasalazine and lung toxicity. Eur Respir J. 2002;19:756-64.

92. Nadarajan P, Fabre A, Kelly E. Sulfasalazine: a rare cause of acute eosinophilic pneumonia. Respir Med Case Rep. 2016;18:35-6.
93. Haroon M, Harney S. A case of severe pulmonary infiltration with eosinophilia (PIE) syndrome induced by sulphasalazine. Int $\mathrm{J}$ Rheum Dis. 2012;15:e150-2.

94. Michel F, Navellou J-C, Ferraud D, Toussirot E, Wendling D. DRESS syndrome in a patient on sulfasalazine for rheumatoid arthritis. Joint Bone Spine; 2005;72(1):82-5.

95. Gutierrez M, Filippucci E, Bugatti L, Bertolazzi C, Grassi W. Severe drug hypersensitivity syndrome due to sulphasalazine in patient with rheumatoid arthritis. Reumatismo. 2009;61:65-8.

96. Schmutz J, Barbaud A, Tréchot P. Hydroxychloroquine and DRESS. Ann Dermatol Venereol. 2008;135:903.

97. Volpe A, Marchetta A, Caramaschi P, Biasi D, Bambara LM, Arcaro G. Hydroxychloroquine-induced DRESS syndrome. Clin Rheumatol. 2008;27:537-9.

98. Català Pérez R, Azón Masoliver A, Hernández Flix S. Interstitial lung disease induced by hydroxychloroquine. Med Clin (Barc). 2015;145:415-6.

99. Lake F, Proudman S. Rheumatoid arthritis and lung disease: from mechanisms to a practical approach. Semin Respir Crit Care Med. 2014;35(2):222-38.

100. Sinagra E, Perricone G, Romano C, Cottone M. Heart failure and anti tumor necrosis factor-alpha in systemic chronic inflammatory diseases. Eur J Intern Med. 2013;24(5):385-92.

101. Daien CI, Monnier A, Claudepierre P, et al. Sarcoid-like granulomatosis in patients treated with tumor necrosis factor blockers: 10 cases. Rheumatology (Oxford). 2009;48(8):883-6.

102. Toussirot E, Pertuiset E. TNFalpha blocking agents and sarcoidosis: an update. Rev Med Interne. 2010;31(12):828-37.

103. Ramos-Casals M, Perez-Alvarez R, Diaz-Lagares C, Cuadrado MJ, Khamashta MA. Autoimmune diseases induced by biological agents: a double-edged sword? Autoimmun Rev. 2010;9:188-93.

104. Liote H, Liote F, Seroussi B, Mayaud C, Cadranel J. Rituximab-induced lung disease: a systematic literature review. Eur Respir J. 2010;35:681-7.

105. Wagner SA, Mehta AC, Laber DA. Rituximab-induced interstitial lung disease. Am J Hematol. 2007;82:916-9.

106. Naqibullah M, Shaker SB, Bach KS, Bendstrup E. Rituximab-induced interstitial lung disease: five case reports. Eur Clin Respir J. 2015;2. doi:10.3402/ ecrj.v2.27178. 
107. Kourbeti IS, Ziakas PD, Mylonakis E. Biologic therapies in rheumatoid arthritis and the risk of opportunistic infections: a meta-analysis. Clin Infect Dis. 2014;58(12):1649-57.

108. Wada T, Akiyama Y, Yokota K, Sato K, Funakubo Y, Mimura T. A case of rheumatoid arthritis complicated with deteriorated interstitial pneumonia after the administration of abatacept. Jpn J Clin Immunol. 2012;35:433-8.

109. Ikegawa K, Hanaoka M, Ushiki A, Yamamoto H, Kubo K. A case of organizing pneumonia induced by tocilizumab. Intern Med. 2011;50:2191-3.

110. Seminario-Vidal L, Cantrell W, Elewski BE. Pulmonary cryptococcosis in the setting of tofacitinib therapy for psoriasis. J Drugs Dermatol. 2015;14(8):901-2.

111. van Vollenhoven RF, Fleischmann R, Cohen $S$, et al. Tofacitinib or adalimumab versus placebo in rheumatoid arthritis. $\mathrm{N}$ Engl J Med. 2012;367(6):508-19.

112. Fleischmann R, Kremer J, Cush J, et al. Placebo-controlled trial of tofacitinib monotherapy in rheumatoid arthritis. $\mathrm{N}$ Engl J Med. 2012;367(6):495-507.

113. Ni Mhuircheartaigh OM, Matteson EL, Green AB, Crowson CS. Trends in serious infections in rheumatoid arthritis. J Rheumatol. 2013;40(5):611-6.

114. Franklin J, Lunt M, Bunn D, Symmons D, Silman A. Risk and predictors of infection leading to hospitalisation in a large primary-care-derived cohort of patients with inflammatory polyarthritis. Ann Rheum Dis. 2007;66(3):308-12.

115. Coyne P, Hamilton J, Heycock C, Saravanan V, Coulson E, Kelly CA. Acute lower respiratory tract infections in patients with rheumatoid arthritis. J Rheumatol. 2007;34(9):1832-6.

116. Wolfe F, Caplan L, Michaud K. Treatment for rheumatoid arthritis and the risk of hospitalization for pneumonia: associations with prednisone, disease-modifying antirheumatic drugs, and anti-tumor necrosis factor therapy. Arthritis Rheum. 2006;54(2):628-34.

117. Bernatsky S, Hudson M, Suissa S. Anti-rheumatic drug use and risk of serious infections in rheumatoid arthritis. Rheumatology (Oxford). 2007;46(7):1157-60.

118. Boling EP, Ohishi T, Wahl SM, Misiti J, Wistar R Jr, Wilder RL. Humoral immune function in severe, active rheumatoid arthritis. Clin Immunol Immunopathol. 1987;43(2):185-94.
119. Wagner UG, Koetz K, Weyand CM, Goronzy JJ. Perturbation of the $\mathrm{T}$ cell repertoire in rheumatoid arthritis. Proc Natl Acad Sci USA. 1998;95(24):14447-52.

120. Fomin I, Caspi D, Levy V, et al. Vaccination against influenza in rheumatoid arthritis: the effect of disease modifying drugs, including TNF alpha blockers. Ann Rheum Dis. 2006;65(2):191-4.

121. Lim WS, Baudouin SV, George RC, et al. BTS guidelines for the management of community acquired pneumonia in adults: update 2009. Thorax. 2009;64(Suppl 3):iii1-55.

122. Muller R, Kallikorm R, Polluste K, Lember M. Compliance with treatment of rheumatoid arthritis. Rheumatol Int. 2012;32(10):3131-5.

123. Hope HF, Bluett J, Barton A, Hyrich KL, Cordingley L, Verstappen SM. Psychological factors predict adherence to methotrexate in rheumatoid arthritis; findings from a systematic review of rates, predictors and associations with patient-reported and clinical outcomes. RMD Open. 2016;2(1):e000171.

124. Lim AY, Gaffney K, Scott DG. Methotrexate-induced pancytopenia: serious and under-reported? Our experience of 25 cases in 5 years. Rheumatology (Oxford). 2005;44(8):1051-5.

125. Leombruno JP, Einarson TR, Keystone EC. The safety of anti-tumour necrosis factor treatments in rheumatoid arthritis: meta and exposure-adjusted pooled analyses of serious adverse events. Ann Rheum Dis. 2009;68(7):1136-45.

126. Galloway JB, Hyrich KL, Mercer LK, et al. Anti-TNF therapy is associated with an increased risk of serious infections in patients with rheumatoid arthritis especially in the first 6 months of treatment: updated results from the British Society for Rheumatology Biologics Register with special emphasis on risks in the elderly. Rheumatol (Oxford). 2011;50(1):124-31.

127. van Dartel SA, Fransen J, Kievit W, et al. Predictors for the 5-year risk of serious infections in patients with rheumatoid arthritis treated with anti-tumour necrosis factor therapy: a cohort study in the Dutch Rheumatoid Arthritis Monitoring (DREAM) registry. Rheumatology (Oxford). 2013;52(6):1052-7.

128. Atzeni F, Sarzi-Puttini P, Botsios C, et al. Long-term anti-TNF therapy and the risk of serious infections in a cohort of patients with rheumatoid arthritis: comparison of adalimumab, etanercept and infliximab in the GISEA registry. Autoimmun Rev. 2012;12(2):225-9.

129. Casulo C, Maragulia J, Zelenetz AD. Incidence of hypogammaglobulinemia in patients receiving 
rituximab and the use of intravenous immunoglobulin for recurrent infections. Clin Lymphoma Myeloma Leuk. 2013;13(2):106-11.

130. van Vollenhoven RF, Emery P, Bingham CO 3rd, et al. Longterm safety of patients receiving rituximab in rheumatoid arthritis clinical trials. J Rheumatol. 2010;37(3):558-67.

131. Bukhari M, Abernethy R, Deighton C, Ding T, Hyrich $\mathrm{K}$, Lunt $\mathrm{M}$, et al. BSR and BHPR guidelines on the use of rituximab in rheumatoid arthritis. Rheumatology (Oxford). 2011;50(12):2311-3.

132. Simon TA, Askling J, Lacaille D, et al. Infections requiring hospitalization in the abatacept clinical development program: an epidemiological assessment. Arthritis Res Ther. 2010;12(2):R67.

133. Ding T, Ledingham J, Luqmani R, et al. BSR and BHPR rheumatoid arthritis guidelines on safety of anti-TNF therapies. Rheumatology (Oxford). 2010;49(11):2217-9.

134. Strangfeld A, Eveslage M, Schneider M, et al. Treatment benefit or survival of the fittest: what drives the time-dependent decrease in serious infection rates under TNF inhibition and what does this imply for the individual patient? Ann Rheum Dis. 2011;70(11):1914-20.

135. RABBIT risk score of infections. RABBIT. 2017. http://www.biologika-register.de/en/home/risk-score/. Accessed 7 Apr 2017.

136. Yun H, Xie F, Delzell E, et al. Risk of hospitalised infection in rheumatoid arthritis patients receiving biologics following a previous infection while on treatment with anti-TNF therapy. Ann Rheum Dis. 2015;74(6):1065-71.

137. Mangtani P, Cumberland P, Hodgson CR, Roberts JA, Cutts FT, Hall AJ. A cohort study of the effectiveness of influenza vaccine in older people, performed using the United Kingdom general practice research database. $J$ Infect Dis. 2004;190(1):1-10.

138. Osterholm MT, Kelley NS, Sommer A, Belongia EA. Efficacy and effectiveness of influenza vaccines: a systematic review and meta-analysis. Lancet Infect Dis. 2012;12(1):36-44.

139. Hak E, Nordin J, Wei F, et al. Influence of high-risk medical conditions on the effectiveness of influenza vaccination among elderly members of 3 large managed-care organizations. Clin Infect Dis. 2002;35(4):370-7.

140. Maruyama T, Taguchi O, Niederman MS, et al. Efficacy of 23-valent pneumococcal vaccine in preventing pneumonia and improving survival in nursing home residents: double blind, randomised and placebo controlled trial. BMJ. 2010;340:c1004.

141. British Society for Rheumatology. Vaccinations in the immunocompromised person-guidelines for the patient taking immunosuppressants, steroids and the new biologic therapies. British Society for Rheumatology, London. 2002. http://www. rheumatology.org.uk/includes/documents/cm_docs/ 2009/v/vaccinations_in_the_immunocompromised_ person.pdf. Accessed 9 Feb 2017.

142. The Joint Committee on Vaccination and Immunisation. Immunisation against infectious disease. Public Health England, London. 2013. https://www. gov.uk/government/publications/immunisationagainst-infectious-disease-the-green-book-front-coverand-contents-page. Accessed 9 Feb 2017.

143. van Assen S, Elkayam O, Agmon-Levin N, et al. Vaccination in adult patients with auto-immune inflammatory rheumatic diseases: a systematic literature review for the European League Against Rheumatism evidence-based recommendations for vaccination in adult patients with auto-immune inflammatory rheumatic diseases. Autoimmun Rev. 2011;10(6):341-52.

144. Shapiro ED, Berg AT, Austrian R, et al. The protective efficacy of polyvalent pneumococcal polysaccharide vaccine. $\mathrm{N}$ Engl J Med. 1991;325(21):1453-60.

145. Kapetanovic MC, Saxne T, Sjoholm A, Truedsson L, Jonsson G, Geborek P. Influence of methotrexate, TNF blockers and prednisolone on antibody responses to pneumococcal polysaccharide vaccine in patients with rheumatoid arthritis. Rheumatology (Oxford). 2006;45(1):106-11.

146. Kaine JL, Kivitz AJ, Birbara C, Luo AY. Immune responses following administration of influenza and pneumococcal vaccines to patients with rheumatoid arthritis receiving adalimumab. J Rheumatol. 2007;34(2):272-9.

147. Bingham CO 3rd, Looney RJ, Deodhar A, et al. Immunization responses in rheumatoid arthritis patients treated with rituximab: results from a controlled clinical trial. Arthritis Rheum. 2010;62(1):64-74.

148. Tay L, Leon F, Vratsanos G, Raymond R, Corbo M. Vaccination response to tetanus toxoid and 23-valent pneumococcal vaccines following administration of a single dose of abatacept: a randomized, open-label, parallel group study in healthy subjects. Arthritis Res Ther. 2007;9(2):R38.

149. Giebink GS, Le CT, Cosio FG, Spika JS, Schiffman G. Serum antibody responses of high-risk children and adults to vaccination with capsular polysaccharides 
of Streptococcus pneumoniae. Rev Infect Dis. 1981;3(Suppl):S168-78.

150. Rytel MW, Dailey MP, Schiffman G, Hoffmann RG, Piering WF. Pneumococcal vaccine immunization of patients with renal impairment. Proc Soc Exp Biol Med. 1986;182(4):468-73.

151. Salemi S, Picchianti-Diamanti A, Germano V, et al. Influenza vaccine administration in rheumatoid arthritis patients under treatment with TNFalpha blockers: safety and immunogenicity. Clin Immunol. 2010;134(2):113-20.

152. Chalmers A, Scheifele D, Patterson C, et al. Immunization of patients with rheumatoid arthritis against influenza: a study of vaccine safety and immunogenicity. J Rheumatol. 1994;21(7):1203-6.

153. Gutierrez-Urena S, Molina JF, Garcia CO, Cuellar ML, Espinoza LR. Pancytopenia secondary to methotrexate therapy in rheumatoid arthritis. Arthritis Rheum. 1996;39(2):272-6.

154. Chakravarty K, McDonald H, Pullar T, et al. BSR/ BHPR guideline for disease-modifying anti-rheumatic drug (DMARD) therapy in consultation with the British Association of Dermatologists. Rheumatology (Oxford). 2008;47(6):924-5.

155. Vial T, Gallant C, Choqu-Kastylevsky G, Descotes J. Treatment of drug-induced agranulocytosis with haematopoietic growth factors: a review of the clinical experience. BioDrugs. 1999;11(3):185-200.

156. Andersohn F, Konzen C, Garbe E. Systematic review: agranulocytosis induced by nonchemotherapy drugs. Ann Intern Med. 2007;146(9):657-65.

157. Aapro MS, Bohlius J, Cameron DA, et al. 2010 update of EORTC guidelines for the use of granulocyte-colony stimulating factor to reduce the incidence of chemotherapy-induced febrile neutropenia in adult patients with lymphoproliferative disorders and solid tumours. Eur J Cancer. 2011;47(1):8-32.

158. Coursin DB, Wood KE. Corticosteroid supplementation for adrenal insufficiency. JAMA. 2002;287(2):236-40.

159. EMA. Rituximab (Mabthera): summary of product characteristics. 2016. http://www.ema.europa.eu/ docs/en_GB/document_library/EPAR_-_Product_ Information/human/000955/WC500054890.pdf. Accessed 7 Apr 2017.

160. EMA. Tocilizumab (RoActemra): summary of product characteristics. 2017. http://www.ema.europa. eu/docs/en_GB/document_library/EPAR_-_Product_
Information/human/000955/WC500054890.pdf. Accessed 7 Apr 2017.

161. Askling J, Fored CM, Brandt L, et al. Risk and case characteristics of tuberculosis in rheumatoid arthritis associated with tumor necrosis factor antagonists in Sweden. Arthritis Rheum. 2005;52(7):1986-92.

162. Ehlers S. Role of tumour necrosis factor (TNF) in host defence against tuberculosis: implications for immunotherapies targeting TNF. Ann Rheum Dis. 2003;62(Suppl 2):ii37-42.

163. Gardam MA, Keystone EC, Menzies R, et al. Anti-tumour necrosis factor agents and tuberculosis risk: mechanisms of action and clinical management. Lancet Infect Dis. 2003;3(3):148-55.

164. Maini R, St Clair EW, Breedveld F, et al. Infliximab (chimeric anti-tumour necrosis factor alpha monoclonal antibody) versus placebo in rheumatoid arthritis patients receiving concomitant methotrexate: a randomised phase III trial. ATTRACT Study Group. Lancet. 1999;354(9194):1932-9.

165. Dixon WG, Hyrich KL, Watson KD, et al. Drug-specific risk of tuberculosis in patients with rheumatoid arthritis treated with anti-TNF therapy: results from the British Society for Rheumatology Biologics Register (BSRBR). Ann Rheum Dis. 2010;69(3):522-8.

166. Tubach F, Salmon D, Ravaud P, et al. Risk of tuberculosis is higher with anti-tumor necrosis factor monoclonal antibody therapy than with soluble tumor necrosis factor receptor therapy: the threeyear prospective French Research Axed on Tolerance of Biotherapies registry. Arthritis Rheum. 2009;60(7):1884-94.

167. Carmona L, Gomez-Reino JJ, Rodriguez-Valverde $\mathrm{V}$, et al. Effectiveness of recommendations to prevent reactivation of latent tuberculosis infection in patients treated with tumor necrosis factor antagonists. Arthritis Rheum. 2005;52(6): 1766-72.

168. Martin-Mola E, Balsa A. Infectious complications of biologic agents. Rheum Dis Clin North Am. 2009;35(1):183-99.

169. Lahiri M, Dixon WG. Risk of infection with biologic antirheumatic therapies in patients with rheumatoid arthritis. Best Pract Res Clin Rheumatol. 2015;29(2):290-305.

170. Kimby E. Tolerability and safety of rituximab $\left(\right.$ MabThera $\left.{ }^{\circledR}\right)$. Cancer Treat Rev. 2005;31(6): 456-73. 
171. Smolen JS, Landewe R, Breedveld FC, et al. EULAR recommendations for the management of rheumatoid arthritis with synthetic and biological disease-modifying antirheumatic drugs: 2013 update. Ann Rheum Dis. 2014;73(3):492-509.

172. Smitten AL, Simon TA, Hochberg MC, Suissa S. A meta-analysis of the incidence of malignancy in adult patients with rheumatoid arthritis. Arthritis Res Ther. 2008;10(2):R45.

173. Mercer LK, Davies R, Galloway JB, et al. Risk of cancer in patients receiving non-biologic disease-modifying therapy for rheumatoid arthritis compared with the UK general population. Rheumatology (Oxford). 2013;52(1):91-8.

174. Nannini C, Medina-Velasquez YF, Achenbach SJ, et al. Incidence and mortality of obstructive lung disease in rheumatoid arthritis: a population-based study. Arthritis Care Res. 2013;65(8):1243-50.

175. Sparks JA, Chang SC, Liao KP, et al. Rheumatoid arthritis and mortality among women during 36 years of prospective follow-up: results from the nurses' health study. Arthritis Care Res. 2016;68(6):753-62.

176. Saevarsdottir S, Wedren S, Seddighzadeh M, et al. Patients with early rheumatoid arthritis who smoke are less likely to respond to treatment with methotrexate and tumor necrosis factor inhibitors: observations from the Epidemiological
Investigation of Rheumatoid Arthritis and the Swedish Rheumatology Register cohorts. Arthritis Rheum. 2011;63(1):26-36.

177. Rojas-Serrano J, Perez LL, Garcia CG, et al. Current smoking status is associated to a non-ACR 50 response in early rheumatoid arthritis. A cohort study. Clin Rheumatol. 2011;30(12):1589-93.

178. Naranjo A, Khan NA, Cutolo $M$, et al. Smoking cessation advice by rheumatologists: results of an international survey. Rheumatology (Oxford). 2014;53(10):1825-9.

179. Harris HE, Tweedie F, White M, Samson K. How to motivate patients with rheumatoid arthritis to quit smoking. J Rheumatol. 2016;43(4):691-8.

180. Aimer P, Stamp L, Stebbings S, Valentino N, Cameron V, Treharne GJ. Identifying barriers to smoking cessation in rheumatoid arthritis. Arthritis Care Res. 2015;67(5):607-15.

181. Aimer P, Treharne GJ, Stebbings S, et al. Efficacy of a rheumatoid arthritis-specific smoking cessation program: a randomized controlled pilot trial. Arthritis Care Res. 2017;69(1):28-37.

182. Iqbal K, Kelly C. Treatment of rheumatoid arthritis-associated interstitial lung disease: a perspective review. Ther Adv Musculoskelet Dis. 2015;7:247-67. 